\title{
ABSCISSION OF ANTHERS IN CECROPIA LOEFL.
}

\author{
C. C. BERG \\ Instituut voor Systematische Plantkunde, Utrecht
}

\begin{abstract}
Abscission of anthers was found in most Cecropia species studied for a taxonomic treatment of this genus for the Amazon region of Brazil*.

Cecropia is a common genus in the neotropics. It comprises about 80 species. Most of them are arborescent pioneer plants and common in more or less open (secondary) vegetation.

The staminate and pistillate inflorescences consist of a cluster of spikes borne on a peduncle and enclosed by a caducous spathe until anthesis. The spikes are mostly stipitate and pendulous due to curvature of the peduncle or the stipe.

The flowers are closely set. In most species the perianth of the staminate flower is tubular and has in its thickened apex a narrow fissure-like aperture. The two stamens of such flowers have applanate filaments of different length before anthesis. The thecae bear a small appendage' Elongation of the filaments pushes the anthers, one after the other, through the narrow aperture. Then the anther is detached by abscission of the uppermost part of the filament.

In most species studied (like $C$. concolor Willd., $C$. latiloba Trécul, and C. ulei Snethlage) the detached anthers become affixed to either the upper margin of the filament or to the margin of the aperture of the perianth by the sticky tips of the appendages of the thecae. These appendages become stringlike and allow motion of the anthers.
\end{abstract}

In $C$. palmata Willd. and $C$. sciadophylla Mart. the anthers remain loosely attached to the filament by a bundle of stretched spiral secondary walls of the tracheary elements of the staminal vascular bundle. In both species the thecae are appendiculate.

C. palmata shows considerable variation in the number of spikes of the staminate inflorescence. The number is often four, and the spikes are thick (up to $\mathrm{ca} .1 .8 \mathrm{~cm}$ ), and the flowers and floral parts are relatively large. When more spikes are present they are thinner and the flowers and floral parts smaller, and, moreover, the number of spiral tracheary elements keeping the anther connected to the filament is smaller. In small flowers the anthers may remain affixed to the flower by appendages of the thecae.

Among the Amazonian Cecropia species $C$. membranacea Trécul proved to be exceptional. In this species the staminate inflorescences bear numerous

* To be published in Acta Amazonica. 


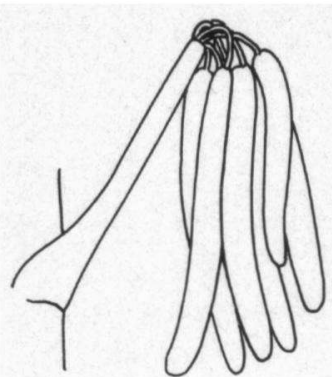

(1)

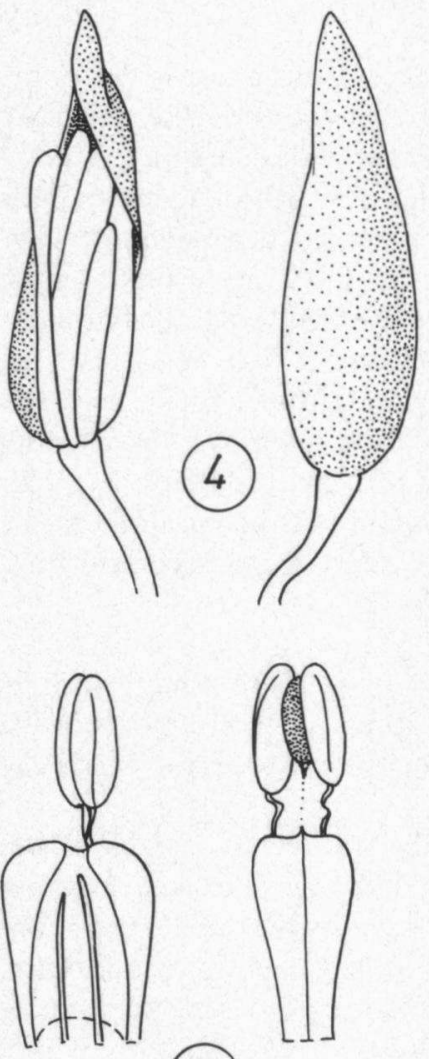

(7)
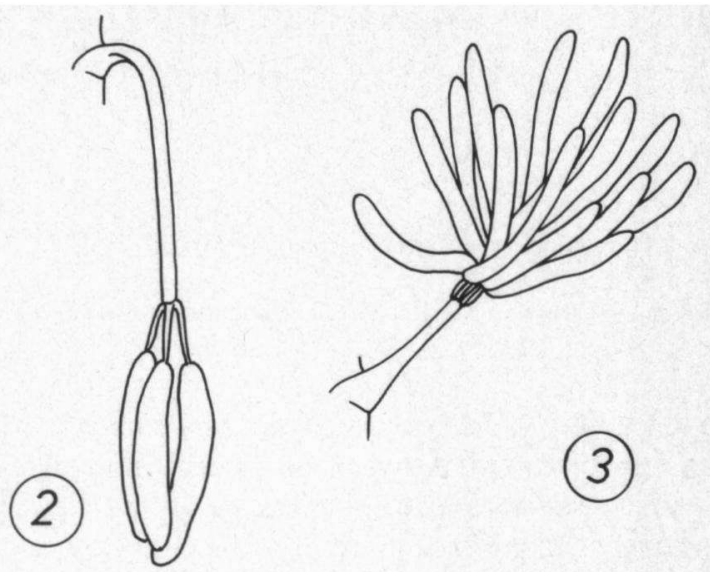

(3)
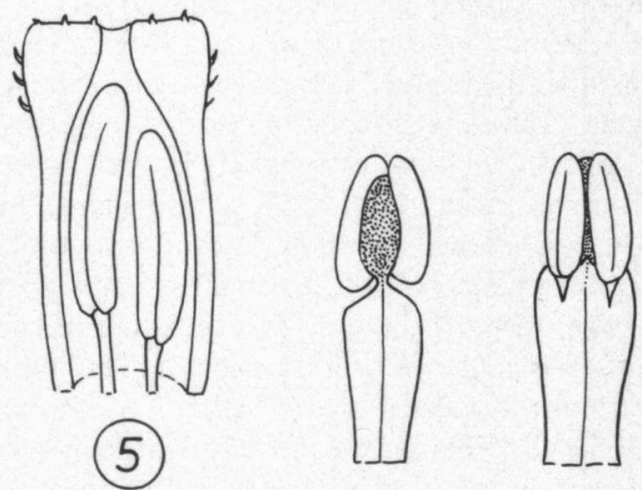

(6)

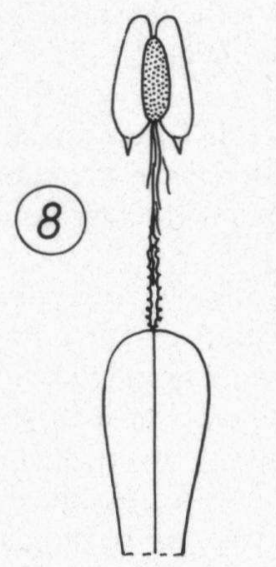

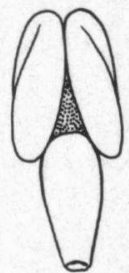

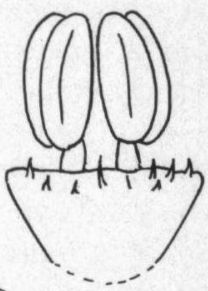

(9)

Fig. 1. Cecropia: 1-3, types of staminate inflorescences; 4, open and closed spathe; 5, staminate flower; 6 , stamens; 7 , detached anthers affixed by appendages of the thecae; 8 , detached anther connected with the filament by a bundle of stretched spiral elements in $C$. palmata; 9, staminate flower and stamen of C. membranacea. 
pendulous spikes which are much thinner than in the other Amazonian species. The small flowers have a cup-shaped perianth with a wide aperture letting through the two stamens which have thick filaments. The anthers, having no appendages, remain attached to their filaments.

Both the common presence of pendulous spikes and the loose affixture of the anthers are suggestive of adaptations to wind pollination. However, both staminate and pistillate inflorescences produce a sweet scent and in staminate inflorescences one can usually find numerous insect larvae.

Whether Cecropia is predominantly anemophilous or entomophilous has still to be established.

In the opinion of the present author Cecropia belongs neither to the Moraceae nor the Urticaceae, but to a separate family Cecropiaceae, which will be published in the near future.

\section{ACKNOWLEDGEMENTS}

The author is indebted to Dr. K. U. Kramer, (Zürich) for the correction of the English text. A grant of the Netherlands Foundation for the Advancement of Tropical Research (WOTRO) enabled the author to investigate Cecropia in Brazil. 